\title{
Urolitiasis en caprinos del Departamento Empedrado (Corrientes, Argentina)
}

\author{
Monzón, N. .; Cipolini, F.'; Martínez, D. ${ }^{1 ;}$ Huber, D. ${ }^{1}$; Robles, C. ${ }^{2}$ \\ ${ }^{1}$ Cátedra Enferm. Infec., Fac.Cs.Veterinarias, UNNE, Cabral 2139, Corrientes, Argentina. \\ ${ }^{2}$ Grupo Salud Anim INTA, Bariloche (Río Negro, Argentina). \\ E-mail: mvnollymonzon $a$ vet.unne.edu.ar
}

\begin{abstract}
Resumen
Monzón, N.; Cipolini, F.; Martínez, D.; Huber, D.; Robles, C.: Urolitiasis en caprinos del Departamento Empedrado (Corrientes, Argentina). Rev. Vet. 31: 2, 152-154, 2020. La urolitiasis es un trastorno obstructivo total o parcial de las vías urinarias, frecuente en pequeños rumiantes en producción intensiva. En una población de 58 caprinos confinados, se detectaron 8 casos de urolitiasis, de los cuales murieron 6 animales afectados (machos castrados). Los caprinos enfermos manifestaron decaimiento, apatía y anorexia. Posteriormente hubo animales que presentaron postura antiálgica (lomo encorvado), abdomen distendido y muy sensible a la palpación, prueba de apnea negativa, respiración superficial y acelerada, así como también balido interrumpido. Se realizaron sondajes uretrales, extracciones de sangre y necropsias a los animales muertos, efectuando las correspondientes tomas de muestras para análisis histopatológicos y de laboratorio. Los resultados obtenidos revelaron la existencia de trastornos obstructivos, lo cual derivó en la reformulación de la dieta de los caprinos y generó el control de la enfermedad, sin posterior aparición de nuevos casos.
\end{abstract}

Palabras clave: caprinos, urolitiasis, obstrucción vías urinarias, reformulación de dieta.

\begin{abstract}
Monzón, N.; Cipolini, F.; Martínez, D.; Huber, D.; Robles, C.: Urolithiasis in goats of the Empedrado Department (Corrientes, Argentina). Rev. Vet. 31: 2, 152-154, 2020. Obstructive urolithiasis is a disease caused by total or partial obstruction of the urinary system, and it is very common in small ruminants under intensive production. In a group of 58 confined goats, 8 of them had this disease, and 6 castrated males, died. Sick animals showed decay, apathy, and anorexia. Afterwards, some animals revealed hunched loin, distended abdomen sensitive to palpation, negative apnea test, superficial and accelerated breathing, as well as interrupted bleat. Urethral sondages, blood testing and necropsies were done to the dead animals, and the corresponding samples were sent to the lab and histopathology analysis. Results revealed obstructive disease, which derived in diet reformulation for disease control, with no further new cases.
\end{abstract}

Key words: caprines, urolithiasis, obstruction of urinary tract, diet reformulation.

\section{INTRODUCCIÓN}

La urolitiasis es un trastorno obstructivo total o parcial de las vías urinarias, común en pequeños rumiantes, sobre todo en producciones intensivas ${ }^{6}$. Se la considera una enfermedad multifactorial donde los desequilibrios minerales, la ingesta de alimentos concentrados, la escasez de agua de bebida y la castración, son algunos de los factores predisponentes ${ }^{3,6}$.

Es una patología muy frecuente en machos y se agrava en animales cuyas dietas contienen altos niveles de concentrados, principalmente sorgo y maiz; así también cuando la relación calcio-fósforo se encuentra mal balanceada y se consumen aguas mineralizadas ${ }^{2,9}$.
Los concentrados en forma de "pellets" favorecen la formación de cálculos debido a la baja producción y escaso flujo de saliva hacia el tracto digestivo, dando como resultado la disminución de la excreción de fósforo por dicha vía y, por lo tanto, aumento de la concentración de este mineral en orina ${ }^{6,9}$. Los urolitos de estruvita son los más frecuentes en animales alimentados a base de granos ${ }^{1,8}$.

\section{MATERIAL Y MÉTODOS}

En un establecimiento agropecuario localizado en Empedrado (Corrientes, Argentina), con una población de 58 caprinos ( 32 hembras y 26 machos castrados) confinados para un ensayo experimental, se detectaron 
8 casos $(13,8 \%)$ de urolitiasis, donde 6 de los afectados murieron, lo cual arroja un tasa de letalidad del $75 \%$.

Los animales eran alimentados con una dieta ajustada al $3 \%$ del peso vivo, constituida a base de un balanceado comercial, específico para la especie y categoría, y como aportante de fibra, alfalfa pelleteada. Los decesos ocurrieron en animales machos en buena condición corporal, en época estival. Inicialmente los animales enfermos manifestaron decaimiento, apatía y anorexia, siendo tratados preventivamente con tilmicosina y oxitetraciclina hasta arribar al diagnóstico.

Posteriormente, al cabo de 3 días, hubieron animales que revelaron sintomatología más específica, compatible con cólico nefrítico y postura antiálgica (lomo encorvado), abdomen distendido y muy sensible a la palpación, prueba de apnea negativa, respiración superficial y acelerada, así como también balido interrumpido.

Estos enfermos fueron sometidos a sondaje uretral y se les aplicó dexametasona como antiinflamatorio. Sólo 2 de ellos se recuperaron. A partir de uno de los sondajes se obtuvieron urolitos (Figura 1), los cuales fueron enviados al laboratorio del Hospital de Clínicas de la Facultad de Ciencias Veterinarias de la UNNE para ser analizados.

A los seis animales muertos se les practicó la necropsia, procediéndose a la toma de muestras de vejiga, riñón y pulmón para análisis histopatológicos y cultivos bacteriológicos. También se colectó orina para la realización de urocultivos y análisis completos de orina en los animales afectados. Todos los caprinos muertos revelaron gran cantidad de líquido en cavidad abdominal, sin evidencias de otras lesiones en órganos abdominales ni torácicos. También se tomaron muestras de sangre para realización de perfiles hemáticos y hepáticos.

Para descartar al agua mineralizada como causa de urolitiasis, se evaluó la existencia de minerales en el agua de los bebederos de los corrales. Considerando la parasitosis como causal de ascitis, se efectuaron análisis coproparasitológicos a todos los caprinos que participaron del ensayo.

\section{RESULTADOS}

Las concreciones analizadas resultaron estar constituídas por fosfato de calcio con $\mathrm{pH} 9$, similar a las halladas en pequeños rumiantes por otros investigadores ${ }^{4}$ . Por estudios histopatológicos se determinó existencia de ruptura de las paredes de la vejiga, con extravasación de glóbulos rojos en la submucosa, leve infiltración de células inflamatorias de tipo polimorfonuclear y pérdida de la continuidad del epitelio. Riñones y pulmones no registraron lesiones microscópicas aparentes.

En cuanto al agua de bebida, se identificaron abundantes algas de género Spirogyra, consideradas no patógenas, así como también escasa cantidad de sales totales. Los exámenes coproparasitológicos revelaron en todos los casos valores inferiores al punto de corte de 1.000 huevos por gramo.

Los cultivos bacteriológicos manifestaron escaso crecimiento de bacilos Gram (-). Los exámenes de orina y urocultivos realizados a uno de los caprinos afectados no revelaron resultados significativos, excepto presencia de abundantes glóbulos rojos.

En lo referente a los resultados hematológicos, todos los animales presentaron niveles elevados de uremia, entre 32 y $128 \mathrm{mg} / \mathrm{dl}$, cuando lo normal para la especie se encuentra en el rango de $12-26 \mathrm{mg} / \mathrm{dl}^{5}$. Todos los animales muertos evidenciaron rotura de vejiga, confirmada por análisis histopatológicos, con consecuentes casos de uroperitoneo (Figura 2) y peritonitis mortales.

\section{DISCUSIÓN}

Todos los animales muertos eran machos castrados y habían revelado condiciones corporales muy buenas, con tamaños mayores con respecto a los de sus compañeros, por lo cual se puede inferir que aquéllos consumían raciones mayores al 3\% del peso vivo, coincidentemente con lo reportado por quienes sugieren que cuando el consumo supera el $2,5 \%$ del peso vivo de la dieta, se predispone la aparición del trastorno obstructivo ${ }^{9}$.

A su vez, esta enfermedad afecta a animales en estabulación y es más frecuente en machos castrados, por

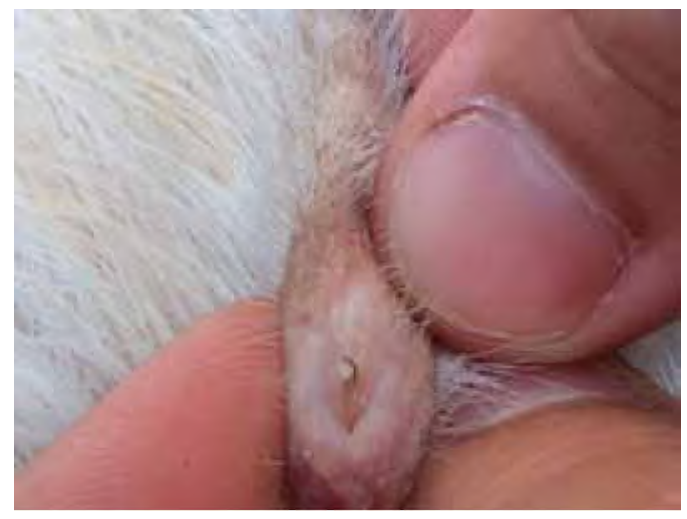

Figura 1: urolito en orificio prepucial.

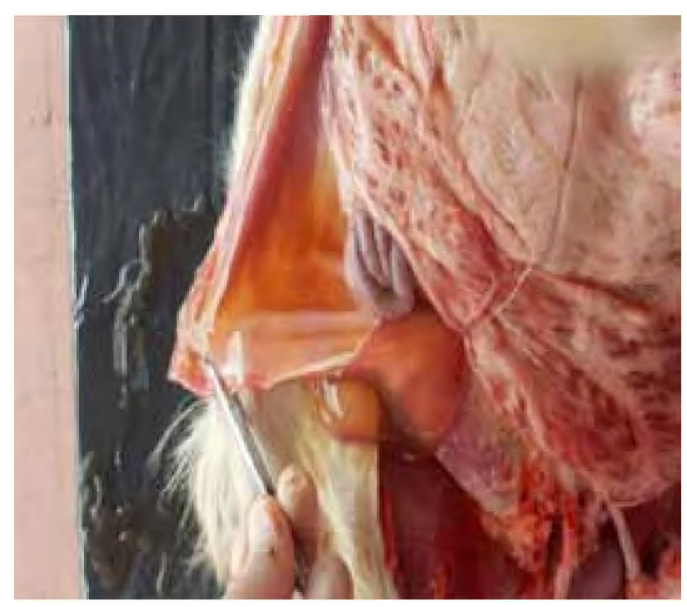

Figura 2: uroperitoneo y peritonitis. 
encontrarse en ellos atrofia de los tejidos de las vías urinarias, lo cual coincide con las condiciones de cría y alimentación del presente reporte ${ }^{7}$.

El consumo de una dieta a base de alfalfa pelleteada y alimento balanceado comercial específico para caprinos, influyeron en la presentación de estos casos clínicos, por ello y en base a las recomendaciones del nutricionista consultado, se modificó la dieta eliminando la alfalfa pelleteada, proporcionando en su lugar rollos de pastura de alta calidad, con el fin de reducir la formación de nuevos cálculos minerales, similar a lo propuesto por otros investigadores ${ }^{10}$.

Además, la época del año en que aparecieron los casos clínicos, coincidió con lo reportado por investigadores que afirman que estos animales son más propensos a enfermarse en verano, ya que se deshidratan por las altas temperaturas ${ }^{6}$.

Luego de las muertes ocurridas, se redujo la dieta a $1,5 \%$ del peso vivo y se alternó la alfalfa pelleteada por rollos de gramíneas ad libitum, con el objeto de estimular la salivación y masticación, teniendo en cuenta que la saliva actúa como una fuente de eliminación muy importante de fósforo hacia el rumen. También se instalaron comederos para administración de cloruro de sodio a efectos de estimular el consumo de agua por parte de los animales, lográndose controlar el problema.

Se concluye que la urolitiasis es una patología que debe tenerse presente debido a las pérdidas que produce en explotaciones caprinas de animales castrados y estabulados, alimentados con dietas mal balanceadas (incorrecta relación calcio-fósforo), que predisponen la aparición de episodios masivos de obstrucciones urinarias.

Agradecimientos: a los veterinarios Cristian Ressel, Carlos Storani, Eduardo Lottero, Roberto Cardozo, Ana Espasandin, Irina Martínez, Pascual Ligios, José Cao, Enrique Yáñez y Javier Lértora, así como a la ayudante alumna Rocío Sandobal, por sus distintas intervenciones durante el periodo relatado.

\section{REFERENCIAS}

1. Abba Y et al. 2015. Clinical management of dietary induced urolithiasis associated with balanoposthitis in a Boer goat. Open Vet J 5: 30-33.

2. Carrillo DF et al. 2015. Urolitiasis en ovinos. Abanico Vet 5: 49-57.

3. Ewoldt J, Jones M, Miesner M. 2008. Surgery of obstructive urolithiasis in ruminants. Vet Clin Food Anim Pract 24: 455-465.

4. Fazili M et al. 2010. Minimally invasive surgical tube cystotomy for treating obstructive urolitiasis in small ruminants with and intact urinary bladder. Vet Record 166 : 528-532

5. George J, Hird D, George L. 2007. Serum biochemical abnormalities in goats with uroliths: 107 cases (19922003). JAm Vet Med Ass 230: 101-106.

6. Gioffreddo JJ. 2011. Sanidad en ovinos y caprinos. Enfermedades metabólicas. FAyV-UNRC (Río Cuarto): www. producción-animal.com.ar

7. Janke $\mathbf{J}$ et al. 2009. Use of Walpole's solution for treatment of goats with urolithiasis: 25 cases (2001-2006). $J$ Vet Med Ass 234: 249-252.

8. Jones M, Streeter R, Goad C. 2009. Use of dietary cation anion difference for control of urolithiasis risk factors in goats. Am J Vet Res 70: 149-155.

9. Radostits OM, Gay CC, Blood DC, Hinchcliff KW. 2002. Medicina Veterinaria: Tratado de las enfermedades del ganado bovino, ovino, porcino, caprino y equino. Ed. McGraw-Hill Interamericana, $9^{\circ}$ ed., Madrid, $2065 \mathrm{p}$.

10. Vanmetre D, Fubini S. 2006. Ovine and caprine urolithiasis: Another piece of the puzzle. Vet Surgery 35: 413-416. 